\title{
Adipokines have a role to play in the treatment of metabolic disease
}

"Up until now drug therapy has failed in making a major impact in the treatment of obesity."

Keywords: adipkines $\approx$ metabolic disease $\approx$ obesity $\approx$ obesity drugs

The world is suffering from an obesity epidemic and most healthcare systems are under tremendous strain to deal with these patients. With obesity comes cardiovascular disease, Type II diabetes, increased cancer incidences and ultimately reduced life expectancy (FIGURE I) [1,2].

Up until now, drug therapy has failed in making a major impact in the treatment of obesity. The most recent drug advances such as Rimonabant $^{\mathrm{TM}}$ and Sibutramine ${ }^{\mathrm{TM}}$ have failed. A surgical approach is another option. Gastric banding, however, is expensive and approximately only $1 \%$ of eligible patients have the surgery. Would this be tolerated if it was hip replacement patients? Treating larger numbers of patients for obesity will require drugs that have fewer side effects with better than $10 \%$ weight loss at reasonable cost.

Adipose tissue was originally thought to be only for storage of triglycerides and nothing else, but advances over the last 15 years have shown that white adipose tissue (WAT) is a major endocrine organ producing clearly indentified adipokines (leptin and adiponectin) and cytokines (TNF- $\alpha$ and IL-6). There is also migration of macrophages and therefore chronic inflammation (FIGURE2) [3].

Understanding these new adipokines and their place in metabolic disease will hopefully lead to new targets and therapies for the treatment of metabolic disease.

\section{Adipokines as possible targets for therapy \\ - Leptin}

Leptin is a $16-\mathrm{kDa}$ nonglycosylated peptide belonging to the cytokine class 1 super family. It was identified as the first adipokine as it is almost exclusively expressed in WAT, particularly in subcutaneous fat (where $80 \%$ of leptin is produced) [4].
Originally thought only to act centrally, it is now clear that it acts peripherally in a large number of tissues, for example adipocytes where it can influence the rate of lipolysis. It also reduces food intake and increases energy consumption, as well as inhibiting orexigenic neuropeptides [5]. Although this protein was not successful when put into clinical practice, it has opened up a field of research that should provide a more targeted approach to obesity treatment.

\section{- Adiponectin}

Adiponectin is a protein produced mainly in WAT that increases fatty acid oxidation while reducing glucose synthesis in the liver [6]. In knock-out mice on a normal diet there is no effect but on a high-fat diet mice develop severe insulin resistance and have lipid accumulation in muscles. These findings suggest that adiponectin has a key role to play in energy balance [7].

There is decreased adiponectin expression observed in obese patients and this is associated with insulin resistance and Type II diabetes. Adiponectin can affect hepatic glucose and decrease mRNA for key gluconeogenisis enzymes [8]. This indicates that it may be a useful target in metabolic disease, especially now two key receptors, adipoR1 and adipoR2 have been shown to play a role in lipid and glucose metabolism, inflammation and oxidative stress. These appear to warrant further investigation.

\section{- Resistin}

In the search for new and improved thiazolidinediones (TZDs), resistin was identified. Resistin is increased in obese animals and decreased in the presence of TZDs; it is also able to decrease glucose transport in vitro [9]. It has the ability to inhibit adipocyte differentiation [10] and therefore may be a good target for the treatement of Type II diabetes. In humans there have

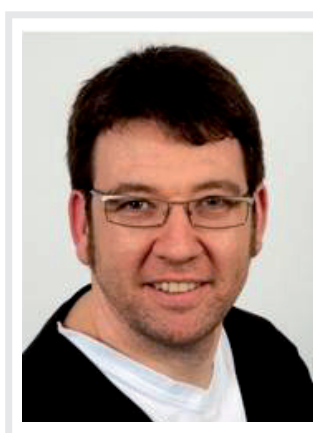

Steve T Russell

Nutritional Biomedicine, School of Life and Health Sciences, Aston University, Aston Triangle, Birmingham, B4 7ET, UK

Tel.: +44 I2I 2044005

E-mail: s.t.russellI@aston.ac.uk 


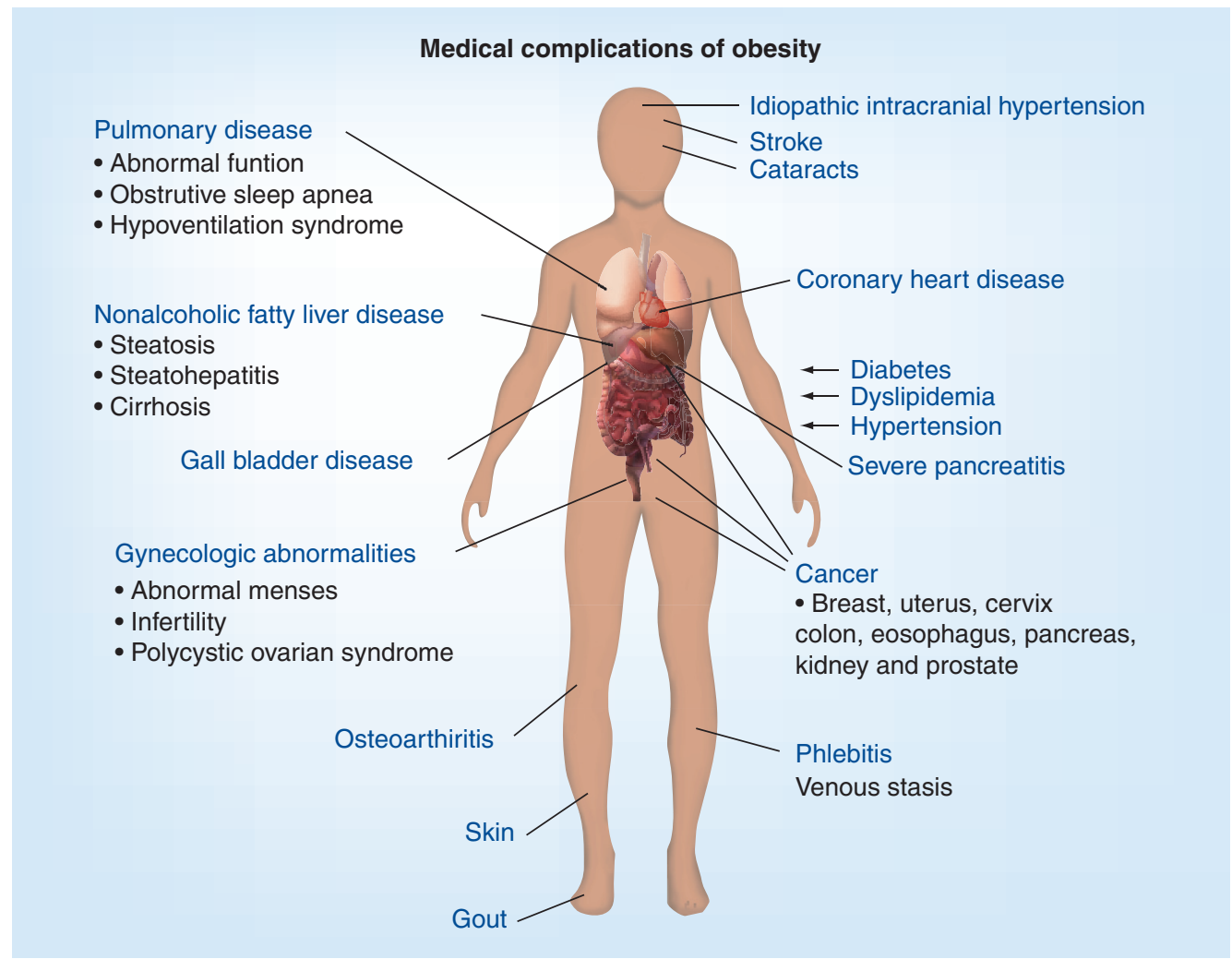

Figure 1. Obesity leads to enormous strain on a great deal of the body's systems leading to cardiovascular disease, diabetes and decreased life expectancy.

been contradictory results. First, there is debate about which organ secretes resistin. Second, there is also debate about the circulating levels in plasma. Further studies are required to elucidate its mechanism of action, however it would appear to be a potential target for therapy.

\section{Zinc- $\alpha 2$-glycoprotein}

Zinc- $\alpha 2$-glycoprotein (ZAG) was identified as playing a role in lipid metabolism and is thought to be responsible for loss of adipose in cancer cachexia patients [11]. ZAG stimulates lipolysis in murine adipocytes by activation of adenylyl cyclase in a GTP-dependent process [12]. ZAG has been shown to be produced in the liver, brown adipose and WAT [12].

Our group has published a number of papers showing reduced weight in normal mice and ob/ob mice when dosed with purified ZAG with improved glucose tolerance $[13,14]$. These treated mice showed increased energy expenditure though increased uncoupling proteins and changes in glucose and fatty acid oxidation.

Moreover, in both cachectic mice [12] and humans [15], expression of ZAG mRNA in WAT was found to be increased tenfold [12] and 2.7-fold [15], respectively. In cachectic cancer patients ZAG mRNA showed a negative correlation with body mass index (BMI), but a positive correlation with weight loss and serum-glycerol levels [15]. In contrast, ZAG mRNA levels in WAT have been shown to be downregulated in obesity and correlated negatively with fat mass, BMI, plasma insulin and leptin [16]. Treatment of $o b / o b$ mice with ZAG decreased body weight and fat mass and improved the parameters of insulin resistance including decreasing plasma levels of glucose, insulin and non-esterified fatty acids, improving insulin sensitivity and increasing muscle mass [14]. While ZAG overexpression in mice reduced both the body weight and weight of epididymal fat [17], ZAG-knockout animals showed an increased body weight, especially when fed a high-fat diet [18]. These results suggest that ZAG, like leptin, is closely associated with fat mass. However, while leptin is positively correlated with fat mass, ZAG is negatively correlated.

\section{The endocannabinoid system}

Endocannabinoids, although not a true adipokine, can influence lipolysis and fatty acid metabolism along with energy balance. Acting 
though the cannaboid receptor (CB1) they can induce glucose uptake and inhibitors can act centrally to suppress appetite [19]

CB1 antagonists (e.g., Rimonabant) decreases body weight and food intake but suppression of other CNS processes leads to suicidal thoughts and depression [20]. Perhaps a more targeted approach is required that avoids the $\mathrm{CB} 1$ antagonist crossing over the blood-brain barrier, or possibly targeting the CB2 receptor.

\section{- Macrophages \& inflammation}

Macrophage infiltration into adipose tissue leads to low-grade chronic inflammation though the production of adipokines, cytokines (TNF- $\alpha$ and IL-6). BMI correlates strongly with the number of macrophages [21], which are shown to decrease after gastric banding [22].

Pro-inflammatory cytokines in adipose tissue may be due to the presence of these macrophages. Also receptors involved in immune response trigger transduction pathways leading to increased expression of pro-inflammatory cytokines, thus decreasing IRS and inhibiting NFкB [23].

Research on adipose tissue and adipokines has changed our understanding of the pathophysiology of obesity and insulin resistance. Macrophage infiltration offers a new target for therapy and shows the need to focus on subcellular structures and intracellular signaling methods.

\section{Future perspective}

Metabolic syndrome, be it insulin resistance, obesity, Type II diabetes or a combination thereof, is a complex medical target that may require a multi-disciplinary approach for effective treatment.

Adipokines offer new targets for therapy. I have only touched on a few key adipokines here and there are more still to be discovered. Ultimately it may mean that a combination of

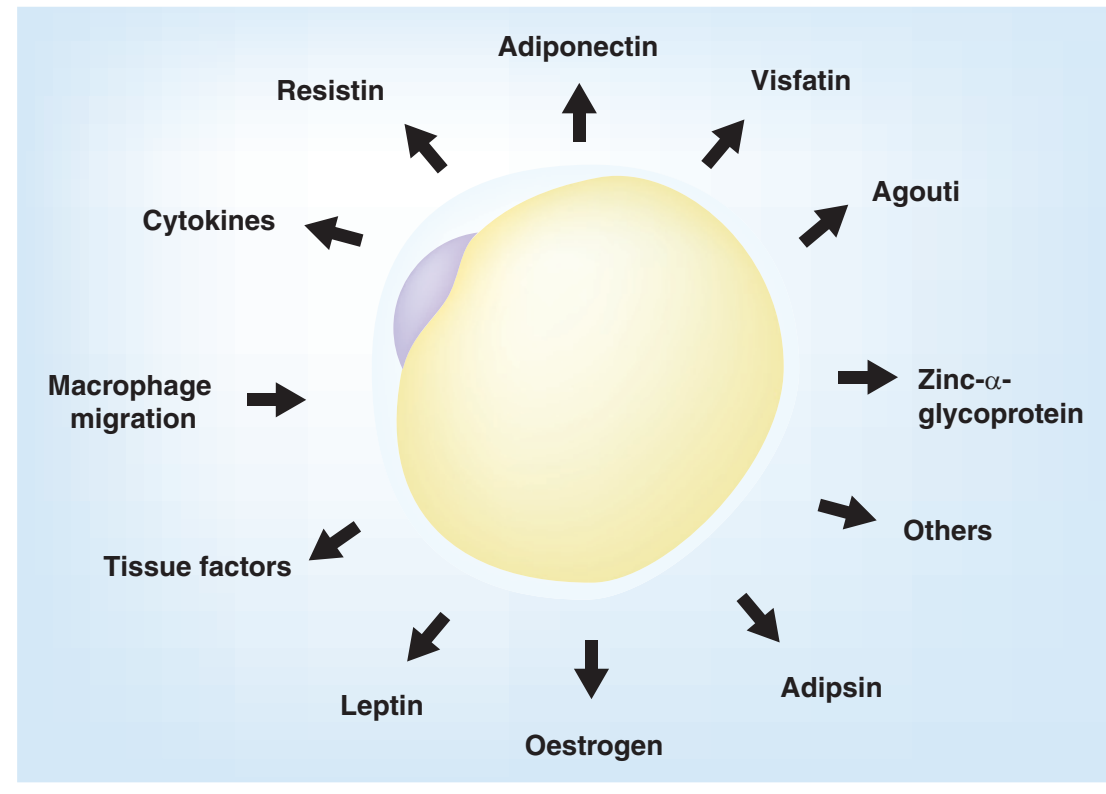

Figure 2. An adipocyte and the factors that are known to be released from adipocytes. These include adipokines, cytokines and other factors that influence energy expenditure and metabolic disease.

drugs is required to effect a change in energy balance for successful weight loss and a normalization of metabolic balance.

Meanwhile, lifestyle changes, cognitive psychotherapy and government intervention may also play a role as health services collapse under the pressure of the obesity epidemic. It is direct intervention through drugs and surgery that will ultimately provide the answers.

\section{Financial \& competing interests disclosure}

The author is funded by Halsa Pharmaceuticals, which holds several patents on the use of Zinc- $\alpha$-glycoprotein in the treatment metabolic disease. The corresponding author is also the co-discoverer on one of these patents. The author has no other relevant affiliations or financial involvement with any organization or entity with a financial interest in or financial conflict with the subject matter or materials discussed in the manuscript apart from those disclosed.

No writing assistance was utilized in the production of this manuscript.

\section{Bibliography}

Papers of special note have been highlighted as:

- of interest

-" of considerable interest

1 Rennie KL, Jebb SA. Prevalence of obesity in Great Britain. Obes. Rev. 6, 11-12 (2005).

- 2 Baskin ML, Ard J, Franklin F, Allison DB. Prevalence of obesity in the United States. Obes. Rev. 6, 5-7 (2005).
Trayhurn P, Wood IS. Adipokines: inflammation and the pleiotropic role of white adipose tissue. Br. J. Nutr. 92, 347-355 (2004).

- 4 Ahima RS, Flier JS. Leptin. Annu. Rev. Physiol. 62, 413-437 (2000)

- 5 Zhang Y, Proenca R, Maffei M, Barone M, Leopold L, Friedman JM. Positional cloning of the mouse obese gene and its human homologue. Nature 372, 425-432 (1994).
-. Kick started the area of adipokine research.

Berg AH, Scherer PE. Adipose tissue, inflammation and cardiovascular disease. Circ. Res. 96, 939-949 (2005).

> Waki H, Yamauchi T, Kamon J. Impaired multimerization of human adiponectin mutants associated with diabetes: molecular structure and multimer formation of adiponectin. J. Biol. Chem. 278, 40352-40363 (2003) 
-8 Kadowaki T, Yamauchi T. Adiponectin and adiponectin receptors. Endocrin. Rev. 26, 439-451(2005)

- Steppan CM, Bailey ST, Bhat S. The hormone resistin links obesity to diabetes. Nature 409, 307-312 (2001).

- Key paper in the link between obesity and diabetes.

$>_{10}$ Kim KH, Lee K, Moon YS, Sul HK. A cysteine-rich adipose tissue specific secretory factor inhibits adipocyte differentiation. J. Biol. Chem. 276, 11252-11256 (2001).

-11 Todorov PT, McDevitt TM, Meyer DJ, Ueyama H, Ohkubo I, Tisdale MJ. Purification and characterization of a tumour-lipid mobilizing factor. Cancer Res. 58, 2353-2358 (1998).

- Key paper in the identification of Zinc- $\alpha 2$ glycoprotein (ZAG).

$\nabla_{12}$ Bing C, Bao Y, Jenkins J. Zinc- $\alpha 2$ glycoprotein, a lipid mobilizing factor, is expressed in adipocytes and is up-regulated in mice with cancer cachexia. Proc. Natl Acad. Sci. 101, 2500-2505 (2004).

13 Russell ST, Zimmerman TP, Domin BA, Tisdale MJ. Induction of lipolysis in vitro and loss of body fat in vivo by zinc- $\alpha 2-$ glycoprotein. Biochim. Biphys. Acta. 1636, 59-68 (2004).

14 Russell ST, Tisdale MJ. Antidiabetic properties of zinc- $\alpha 2$-glycoprotein in ob/ob mice. Endocrinol 151, 948-957 (2010).

- Shows link between ZAG and diabetes.
15 Mracek T, Stephens N, Gao D et al. Zinc- $\alpha 2$-glycoprotein in adipose atrophy in human cancer cachexia. Presented at: The 5th Cachexia Conference. Barcelona, Spain, 5-8 December (2009).

- Key paper linking ZAG with human cachexia.

16 Mracek T, Ding Q, Tzanavari T et al. The adipokine zinc- $\alpha 2$-glycoprotein is downregulated with fat mass expansion in obesity. Clin. Endocrinol. 72, 334-341 (2010).

17 Gong F-Y, Zhang S-J, Ding J-Y et al. Zinc- $\alpha 2$-glycoprotein is involved in regulation of body weight through inhibition of lipogenic enzymes in adipose tissue. Int. J. Obese. 33, 1023-1030 (2009).

- Key paper linking ZAG with human obesity.

18 Rolli V, Radosavljevic M, Astier V et al. Lipolysis is altered in MHC Class I zinc- $\alpha 2$-glycoprotein deficient mice. FEBS Lett. 581, 394-400 (2007).

19 Vettor R, Pagano C. The role of the endocannabinoid system in lipogenesis and fatty acid metabolism. Best Pract. Res. Clin. Endocrinol. Metab. 23, 52-63 (2009).

- Excellent review of the subject area.
20 Després JP, Van Gaal L, Pi-Sunyer X, Scheen A. Efficacy and safety of the weight-loss drug rimonabant. Lancet. 371(9612), 555 (2008).

- Important safety implications for a key weight-loss drug.

-21 Trayhurn P, Wood IS. Signalling role of adipose tissue: adipokines and inflammation in obesity. Biochem. Soc. Trans. 33, 1078-1081 (2005).

22 van Dielen FMH, Buurman WA, Hadfoune M, Nijhuis J, Greve J. Macrophage inhibitory factor, plasminogen activator inhibitor-1, other acute phase proteins and inflammatory mediators normalize as a result of weight loss in morbidly obese subjects treated with gastric restrictive surgery. J. Clin. Endo. Met. 89(8) 4062-4068 (2004)

23 de Luca C, Olefsky JM. Inflammation and insulin resistance. FEBS Lett. 582(1), 97-105 (2008). 